
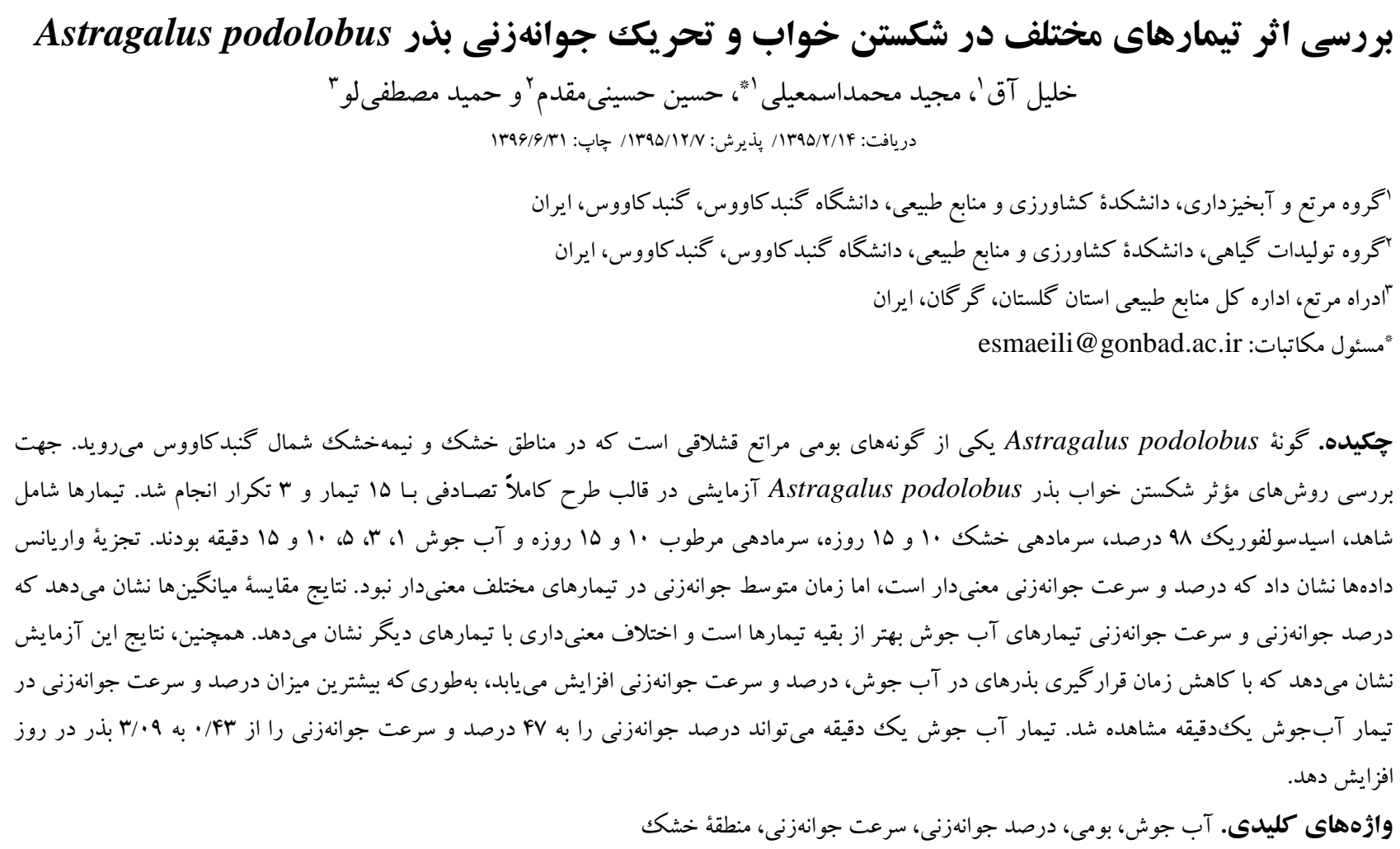

\title{
The effect of different treatments on seed dormancy and germination of
} Astragalus podolobus

\author{
Khalil Agh ${ }^{1}$, Majid MohammedEsmaeili ${ }^{1 *}$, Hossein Hossinimoghaddam² \& Hamid Mostafalo ${ }^{3}$ \\ Received 04.05.2016/ Accepted 26.02.2017/ Published 22.09.2017
}

${ }^{1}$ Department of Range and Watershed Management, Faculty of Agriculture and Natural Resources, University of Gonbad-e Kavous, Gonbad-e Kavous, Iran

${ }^{2}$ Department of Plant Production, Faculty of Agriculture and Natural Resources, University of Gonbad-e Kavous, Gonbad-e Kavous, Iran

${ }^{3}$ Department of Natural Resources, Golestan Province, Gorgan, Iran

${ }^{*}$ Correspondent author: esmaeili@gonbad.ac.ir

\begin{abstract}
The species Astragalus podolobus is one of the endemic species of winter pastures that grows in arid and semi-arid areas in the north of Gonbad-e Kavous. To investigate effective methods of breaking seed dormancy of Astragalus podolobus, an experiment was carried out in the framework of a completely randomized design with 15 treatments and 3 replications. Treatments included controls, 98\% sulfuric acid, dry chilling for 10 and 15 days, wet chilling for 10 and 15 days, and boiling water 1, 3, 5, 10 and 15 minute, respectively. Analysis of variance showed that the percentage and speed of germination were significant in different groups while the average time of germination in different treatments was not significant. The results of comparing mean values showed that the percentage and the speed of germination in boiling water treatments were best in comparison with other treatments with significant differences. The results of this experiment also showed that reducing the exposure time of seeds to boiling water increases the germination percentage and speed, consequently, the highest percentage and speed of germination was observed in boiling water 1 minute. Boiling water 1 minute treatment can increase the germination percentage up to $47 \%$ and the seed germination speed from 0.43 to 3.09 seeds per day.
\end{abstract}

Keywords. boiling water, endemic, germination percentage, speed of germination, arid 
بوتهاى، با ارتفاع · V سانتىمتر، قطر تاج يككمتر، بسيار خوش-

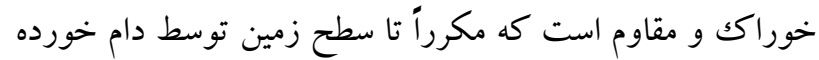

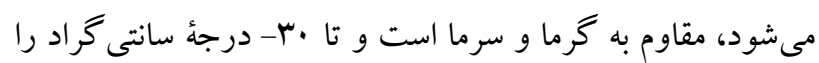

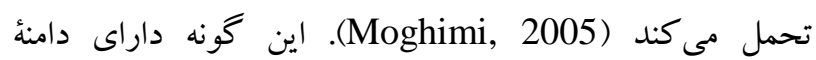
زيستمحيطى بسيار وسيعى است، بهطورى كه در مناطق نيمه -

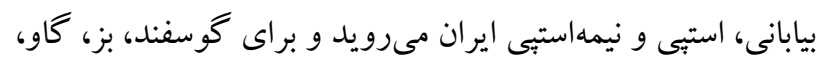
آهو و زنبور عسل مناسب است (Faizi, 2004). در استان كلستان

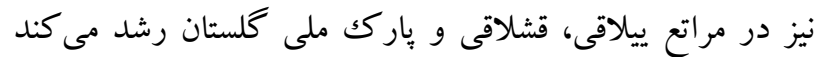
(Hosseini, 2012). اين گونه محافظ خاك است و علوفئ

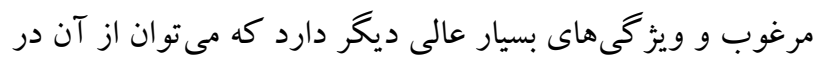

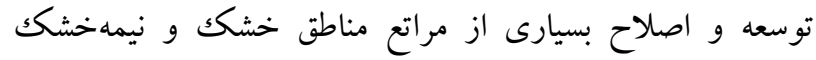

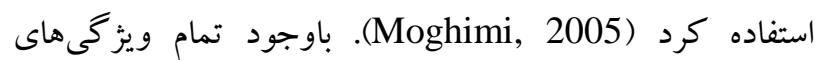

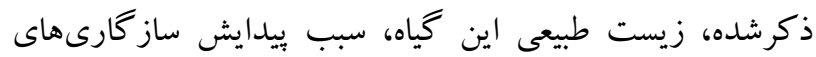
خواب بذر شده است. جنين يديدهاى، ضمن اينكه براى بقا و

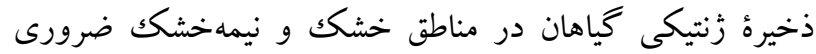
است، مىتواند سبب بروز مشكل جدى در تكثير و اهلى كردن كياهان شود، بهطورى كه بذر بسيارى از اين گياهان حتى در

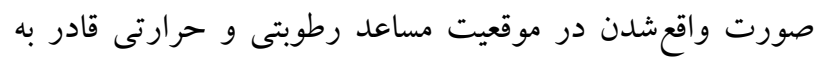

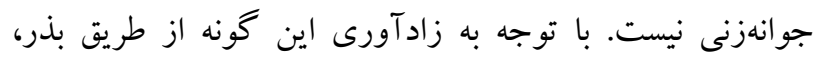

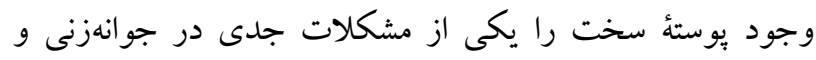
تكثير اين گياه مىداند. علت اصلى سختى را نيز به ويز گیىهاى شيميايى و فيزيكى يوستهُ بذر نسبت مىدهند ( Tran \&

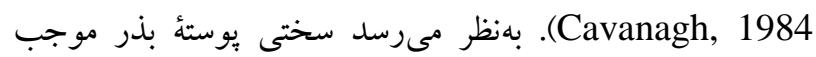

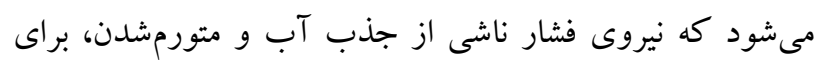

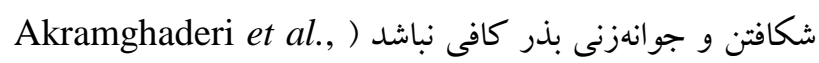

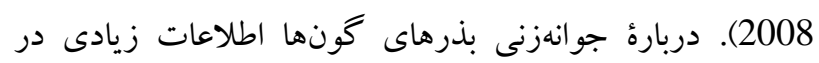

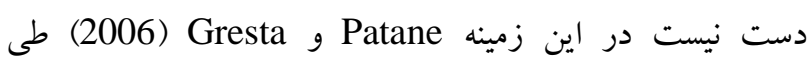

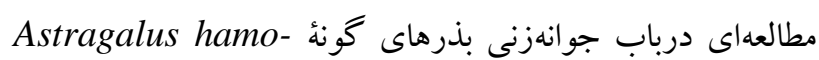

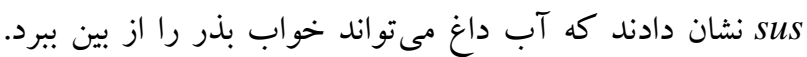

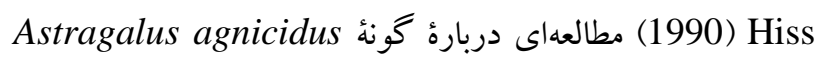
انجام و نشان داد خراشدهى شيميايى در اسيد سولفوريك دورك مىتواند M/D درصد جوانهزنى ايجاد كند درحالى كه، در تيمار

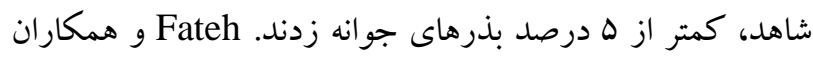

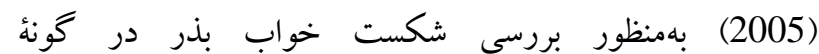
Astragalus tribuloides از تيمار سرمادهى و نفوذيذيركردن إن برن

\section{مقلمهه}

افزايش جمعيت كشور ايران در جند دهؤ گذشته و بهدنبال آن،

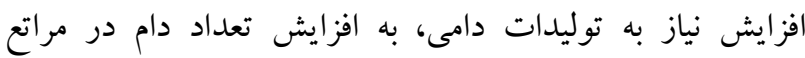

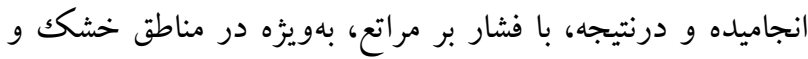

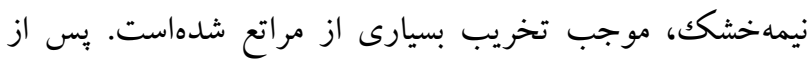

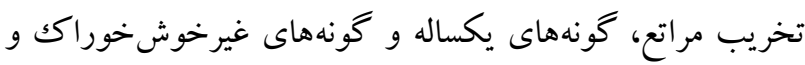

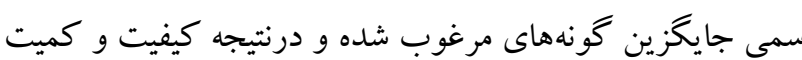
علوفه در قسمت اعظم اين مراتع به هيجوجه رضايتبخش نيست و

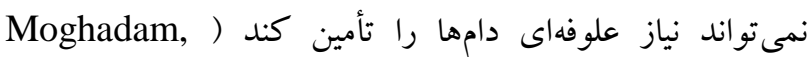
1998). بسيارى از مراتع مناطق خشك و نيمه تشك بله بهلت

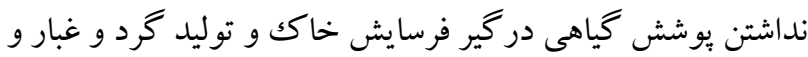

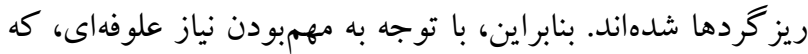
اقتصاد بسيارى از خانوارهاى ايرانى بدان وابسته است، و نيز فرسايش خاكك و گردوغبار در مناطق خشك و نيمهخكن، در

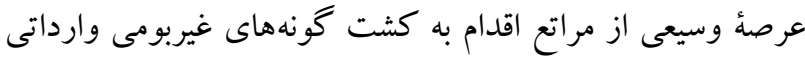

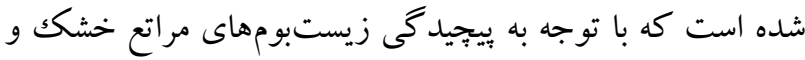
نيمهخشك مشكلات خاص خود را بهوجود آوردهاند. مثلاً در

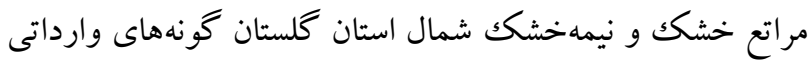
آترييلكس كشت مى شود كه با وجود توليد علوفة مناسب و ديخر

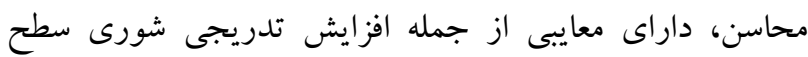

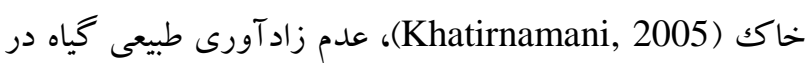
سالهاى بِ از استقرار، ايجاد اختلالات متابوليكى در دامها، اثر

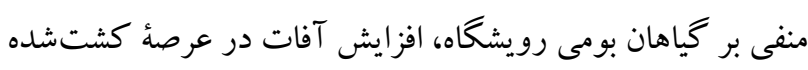

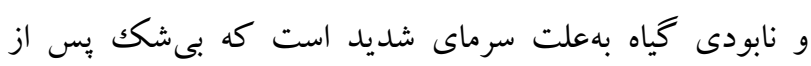

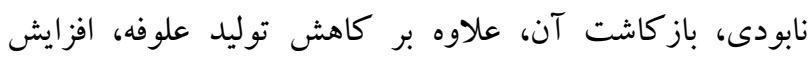
هزينهاى اقتصادى نيز دريى خواهد داشت ( Azarnivand \&

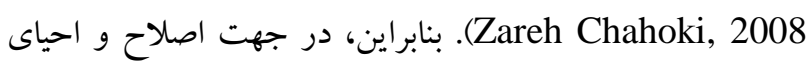
مراتع خشك و نيمه خشك، نياز به معرفى، تكثير و استقرار

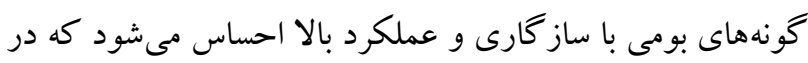

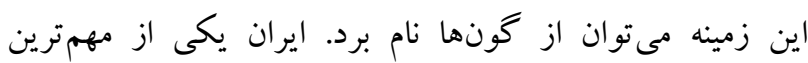

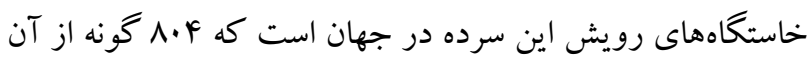

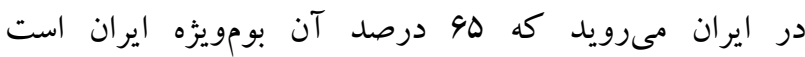
(Maassoumi, 2006)

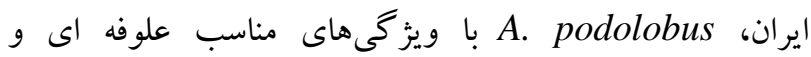
ساز گارى بالا در مناطق خشك و نيمه خشك نام برد. اين گونه 
است. Keshtkar و همكـــاران (2009) شكـــت خــواب و

Ferula g Ferula gummosa جوانسهزنسى بذرهايى assafoetida

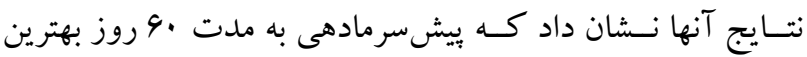

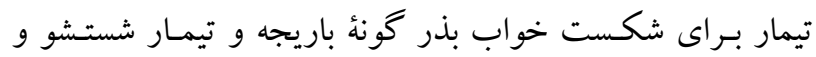

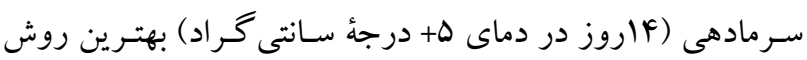
بر اى شكستن خواب بذر گونهُ آنقوزه (Ferula. assafoetida)

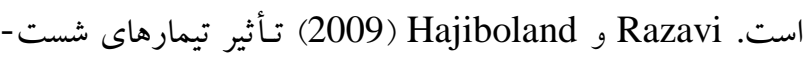
وشو، خراشدهى، سـرمادهى، دمـا و GA3، برشكست خواب بذر

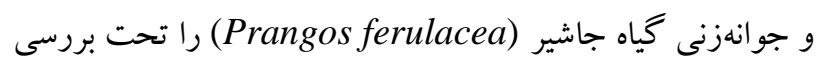
قرار دادند. نتايج نشان داد كه سرمادهى در ه و r ا درجةُ سانتى-

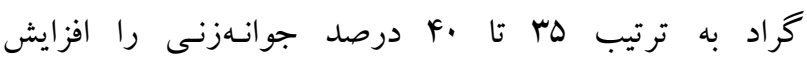

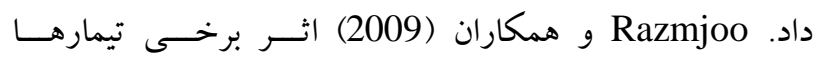

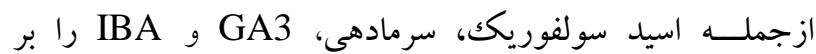

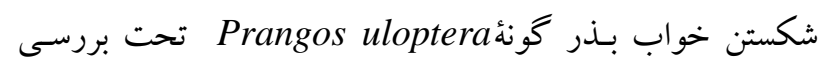
قرار دادنـد. نتايج بيانكر بالاترين ميزان جوانهزنى در اثر تيمار

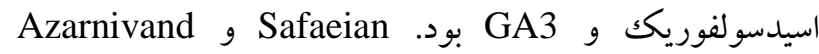
(2010) در بررسى تأثير برخى تيمارها بر شكست خواب و بهبود جوانهزنى بذر گياه جاشير (Prangos ferulacea) به اين نتيجه

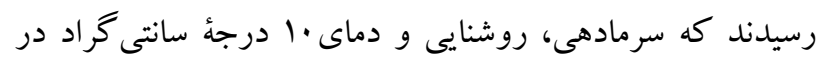

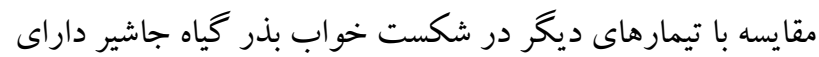
تأثير معنىدارى است. Amouaghaei (2007) در مطالعـأ بيولوزيكى خود دربارهُ افراد تيرهُ جتريان اثر سرمادهى را بهترين تيمار براى شكستن خـواب بـذر افراد ايـن تيـره تسشخيص داد. در

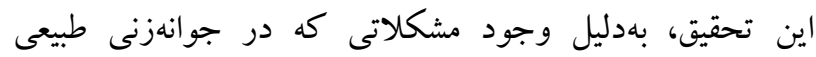
بذرهاى كونه شمال شهرستان گنبدكاووس وجود دارد، به بررسى اثر تيمارهاى

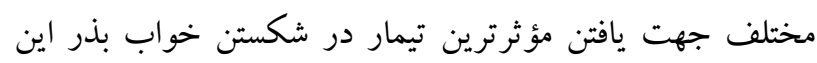
كونه برداخته شد.

\section{مواد و روشها}

تحقيق حاضر به منظور تعيين روشهاى مناسب جهت شكستن

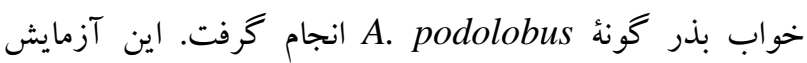

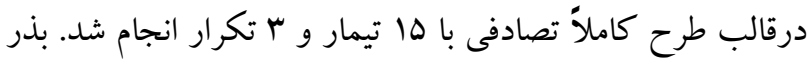
اين گونه از مر اتع خشك و نيمه خشك شمال شهر ستان گنبد -

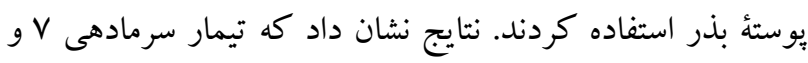

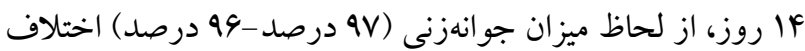
معنىدارى با ساير تيمارها دارد. Esavand و همكاران (2005) براى بررسى جوانهزنى و شكستن خواب بذر

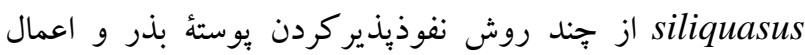

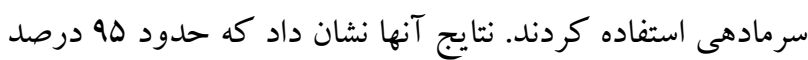

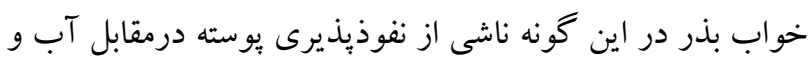

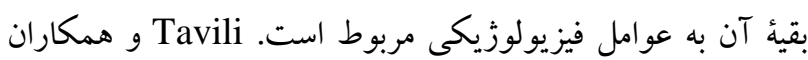

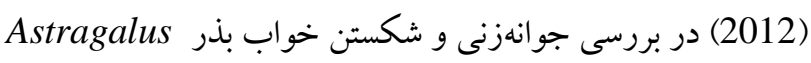

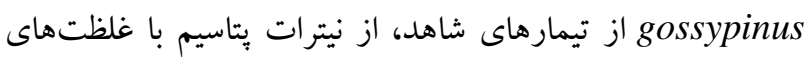

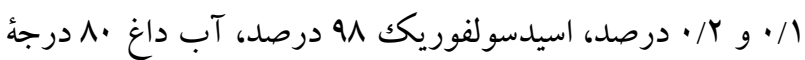

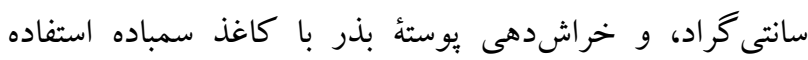

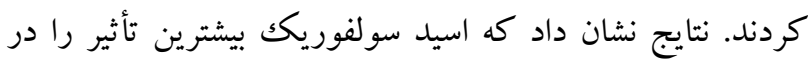
جوانهزنى دارد. Moshtaghian و همكاران (2009) براى

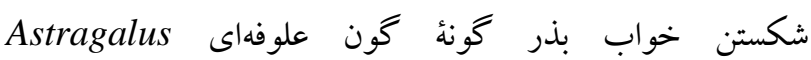

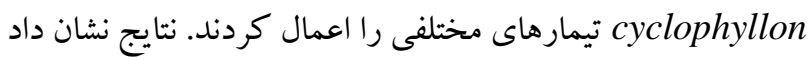
كه جوانهزنى در تيمار خاكك سرد كمترينهُ و جوانهزنى با تيمار اسيد سولفوريكك ه1/· بهترين نتيجه را مىدهد. Alebrahim و همكاران (2010) در بررسى شكستن خواب بذر علف هرز تلخه از اسيد سولفوريكك غليظ در زمانهاى (Acroptilon repens) مختلف استفاده كردند و به اين نتيجه رسيدند كه ·r دقيقه

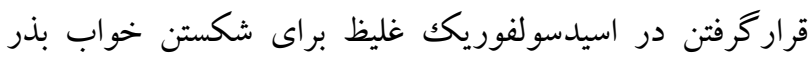
لازم است. Pouresmaeil و Sharifi (2013) طى بررسى

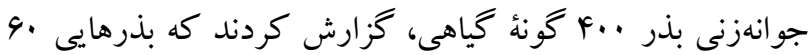

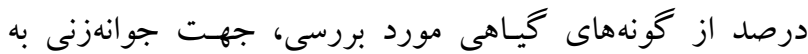

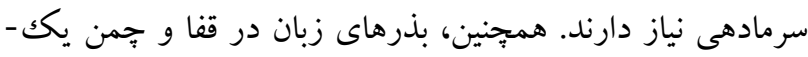

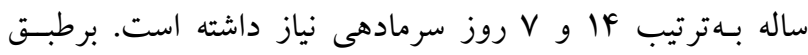
نظريسهاى كـه بـسيارى ازمتخصصان مسائل بذر مقبول است،

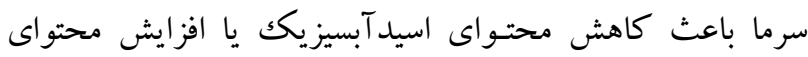

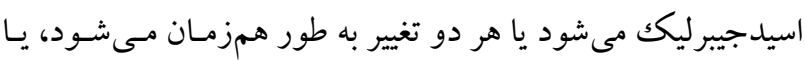

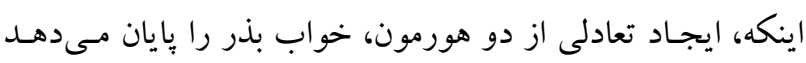

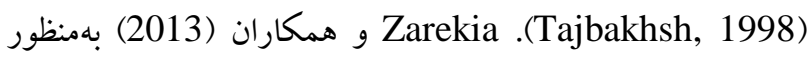

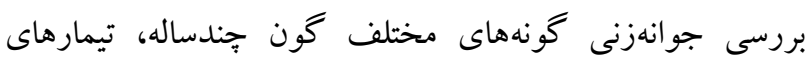
خراشدهى و سرما را در بذر 4 كونه مورد مطاله قرار دادند و نتيجه

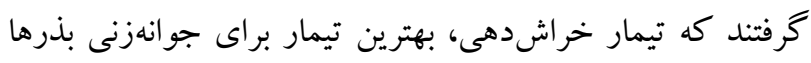


مقطر، به عنوان بستر مناسب جوانهزنى استفاده شد. آزمايش همهٔ تيمارها بهصورت همزمان صورت گرفت. تعداد بذر در هر تكرار

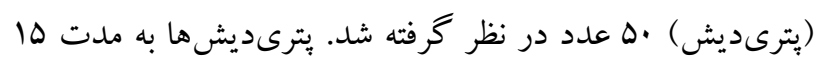
روز در داخل اتاقك رشد با با ساعت روشنايى در دماى لهرك درجة سانتى گراد و ر I ساعت تاريكى در دماى ها درجة سانتى گراد قرار داده شد. شمارش بذرهاى جوانهزده از روز اول آزمايش بهمدت ها روز بهصورت روزانه ادامه يافت. تأمين

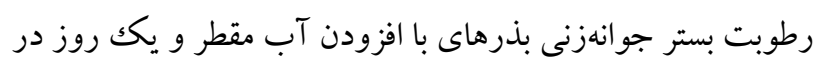

ميان انجام شد. درصد جوانهزنى براساس رابطة إبدست آمد: n/N*100 (1) كه در آن n تعداد بذرهاى جوانهزده و N تعداد كل بذرهاى است

.(Tavili et al., 2012) سرعت جوانهزنى از رابطهُ ب بهدست آمد: SNi/Di (r) كه در آن Ni تعداد بذر جوانهزده در هر روز و Di شمارهُ روز پيس از شروع آزمايش است. سرعت جوانهزنى براساس بذر در روز است (Arbabian et al., 2009). زمان متوسط جوانهزنى از

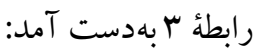

(r) كه در آن D تعداد روزها ييش از شروع جوانهزنى، N تعداد بذرهاى جوانهزده در روز Dام و n تعداد كل بذرهاى جوانهزده Tavili, ) است. زمان متوسط جوانهزنى براساس روز است .(2014

در اين مطالعه براى تجزيه آمارى دادهها از نرمافزار SPSS استفاده شد. تجزئٌ واريانس دادهها در سطح ا درصد و مقايسٔ ميانخين ها در سطح ه درصد، با استفاده از آزمون دانكن انجام شد.

نتايج

نتايج حاصل از تجزئه واريانس دادهها در سطح ا درصد نشان

A. Aاد كه بين تيمارهاى مختلف شكستن خواب بذر كونج podolobus وجود دارد. اما از نظر زمان متوسط جوانهزنى، تفاوت معنىدارى بين تيمارهاى مختلف مشاهده نشد (جدول (). مقايسٔ ميانخينهاى
كاووس واقع در استان كلستان جمع آورى شد و آزمايشهاى شكست خواب در آزمايشگاه زيستشناسى مرتع دانشگاه كنبد كاووس انجام شد. تيمارهاى مختلف شكستن خواب عبارت-

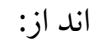
- تيمارشاهد،

- تيمار بذر با اسيدسولفوريك يمه ده درصد بهمدت ه دقيقه، - تيمار بذر با سرمادهى خشك در دماى Y-Y درجهُ سانتى گر اد به-

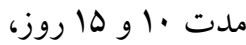
- تيمار بذر با سرمادهى مرطوب در دماى F-Y درجهُ سانتى گراد

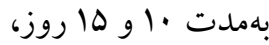

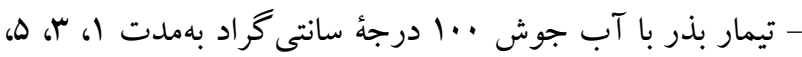

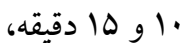
- تيمار بذر غلافدار با اسيدسولفوريك ه ه درصد بهمدت هه دقيقه، - تيمار بذر غلافدار با آب جوش · · إ درجه سانتى گراد بهمدت

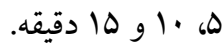
جهت ضدعفونى كردن پيترىديش و كاغذ صافى از دستگاه

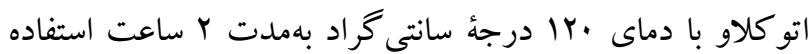
شد. در تيمار اسيدسولفوريكك، بذرهاى به مدت هه دقيقه در اسيد سولفوريك هو درصد قرار گرفتند و بس از شستوشو با آب مقطر به يترىديش منتقل شدند. در تيمار سرمادهى خشكك، بذرهاى به مدت ·ل و ها روز در داخل نايلون در يخجال با دماى F-F درجه سانتى گراد قرار داده شده و ستبس به يترىديش منتقل شدند. در تيمار سرمادهى مرطوب، بذرها بهمدت ·ل و ها روز در داخل

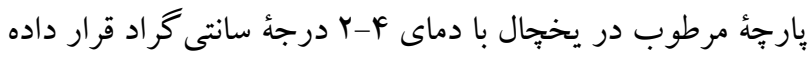
شده و سيس به يترىديش منتقل شدند. در تيمار آب جوش، بذرهاى به مدت ا، اه، ه، ·ل و ها دقيقه در آب جوش با دماى I . . شدند. در تيمار اسيد سولفوريكك براى بذرهاى غلاف دار، بذرها با غلاف بهمدت هد دقيقه در اسيدسولفوريكك \ه درصد قرار گرفتند و بس از شستوشو با آب مقطر به بترىديش منتقل شدند. در تيمار آب جوش براى بذرهاى غلافدار، بذرها با غلاف بهمدت ه، ·

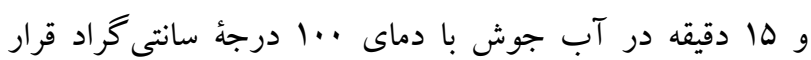
كرفتند و سبس به بِترىديش منتقل شدند. در همهُ بترىديش ها از كاغذ صافى واتمن (Watman)، يس از مرطوبشدن با آب 
جدول ا- تجزئ واريانس درصد، سرعت و زمان متوسط جوانهزنى بذر A. podolobus در تيمارهاى مختلف.

Table 1. Analysis of variance, percentage of speed and time of A. podolobus seed germination in different treatments.

\begin{tabular}{|c|c|c|c|c|c|}
\hline $\mathbf{F}$ & $\begin{array}{c}\mathbf{P} \\
\text { (سطح اطمينان) }\end{array}$ & ميانگين مربعات & درجة آزادى & منابع تغيير & فاكتورهاى مورد \\
\hline \multirow[t]{2}{*}{ V/Aq.*** } & $\cdot / \cdots$ & $r / \pi / T$ & $1 \varepsilon$ & تيمارها & درصد جوانهزنى \\
\hline & & $\cdot / T 9 \varepsilon$ & $r$. & خطاى آزمايش & \\
\hline \multirow[t]{2}{*}{$\Lambda / T V 1^{* *: *}$} & $\cdot / \cdots$ & $\cdot / 791$ & $1 \varepsilon$ & تيمارها & سرعت جوانهزنى \\
\hline & & $\cdot / \cdot \wedge \varepsilon$ & $r$. & خطاى آزمايش & \\
\hline \multirow[t]{2}{*}{$1 / 291^{\text {ns }}$} &.$/ 1 V 0$ & $17 / r 91$ & $1 \varepsilon$ & تيمارها & زمان متوسط \\
\hline & & $1 . / 4 r \varepsilon$ & $r$. & خطاى آزمايش & جوانهزنى \\
\hline
\end{tabular}

n.s and ** are respectively insignificant and significant in the statistical error probability level of $1 \%$

مشابه با رويشگاه طبيعى گياه در نظر گرفته شود. در اين آزمايش با توجه به محيط رويشگاه گونه نيمه خشك شمال شهرستان گنبد كاووس ويز گى هاى گرما، سرما و خشكى در تيمارها در نظر كرفته شد.

A. در اين آزمايش، ها تيمار براى شكستن خواب بذر در كونه podolobus درجه سانتى گراد اثر مثتى بر افزايش درصد و سرعت جوانهزنى بذرها نشان دادند. افزايش درصد و سرعت جوانهزنى بذرها در اثر اعمال تيمار آبجوش را مىتوان به نرمشدن و نفوذيذيرشدن A. يوسته بذر نسبت داد، جرا كه يوسته سخت بذر كياه podolobus شده كه اين امر امكان نفوذ آب به داخل بذر را فراهم مى كند و همجينين با نرمشدن يوسته بذر، امكان متورمشدن و رشد براى

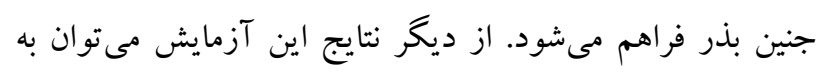
كاهش ميزان جوانهزنى بذرها با افزايش مدت زمان قرارگيرى بذرهاى در آب جوش اشاره كرد كه احتمالاً بهعلت دماى بالاى آبجوش و تأثير منفى آن بر ساختار جنين بذر است. كه احتمالاً دماى بالاى آب جوش با آسيبرساندن به ساختار جنين بذر موجب كاهش درصد و سرعت جوانهزنى بذرها مىشود. از نتايج ديخر اين آزمايش مىتوان به كاهش شديد درصد و سرعت جوانهزنى بذرهاى داراى غلاف، تحت تيمار آبجوش اشاره كرد، درصورتى كه همين بذرها، بدون غلاف تحت تيمار آبجوش داراى بيشترين ميزان جوانهزنى بين تيمارها بودند كه علت را مىتوان تنها به وجود مواد بازدارندهُ شيميايى نسبت داد. كاهش شديد در ميزان جوانهزنى بذرهاى غلافدار تحت تيمار
درصد جوانهزنى در سطح ه درصد نشان داد كه تمامى تيمارهاى آبجوش نسبت به تيمارهاى ديخر برترى دارند. همجنين با كاهش زمان قرارگيرى بذرها در آب جوش، درصد جوانهزنى افزايش يافته است، بهطورى كه تيمار آبجوش يككدقيقه، درصد جوانهزنى بذرها را از ا درصد به FV درصد در تيمار شاهد افزايش

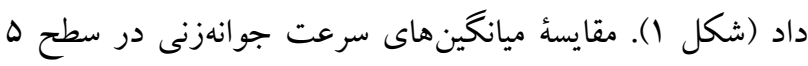
درصد نشان داد كه تنها تيمارهاى آبجوش ا و ب دقيقه تفاوت معنى دارى با تيمار شاهد دارند. همجينين، نتايج نشان مىدهد كه با كاهش زمان قرارگرفتن بذرها در آبجاشوش سرعت جوانهزنى افزايش مىيابد، بهطورى كه تيمار آبجوش يككدقيقه، سرعت

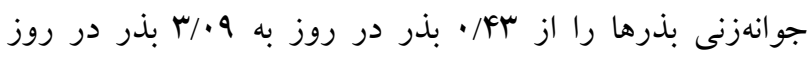
افزايش داد (شكل Y). مقايسٔ ميانگين هاى زمان متوسط جوانهزنى در سطح ه درصد نشان داد كه بين تيمار شاهد و بقئ تيمارها تفاوت معنى دارى وجود ندارد (شكل r).

\section{بحث و نتيجه Fيرى} تكثير گياهان از طريق بذر ساده و ارزان است اما خواب بذر در

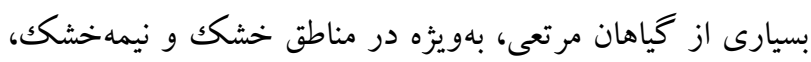
تكثير و اهلى شدن كياهان را با مشكل مواجه مى كند. بنابراين، يافتن تيمارى مناسب براى شكستن خواب الزامى است. بذرها در مناطق خشكك و نيمهخشك، تحت تأثير مجموعهاى از عوامل محيطى قرار دارند و معمولاً شرايط طبيعى هر منطقه مناسبترين تيمار خوابشكنى را براى بذرهاى گياهان آن منطقه فراهم مى كند بنابراين، توصيه مىشود جهت شكستن خواب بذر گونهايى كه

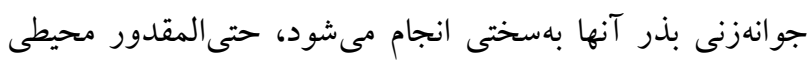




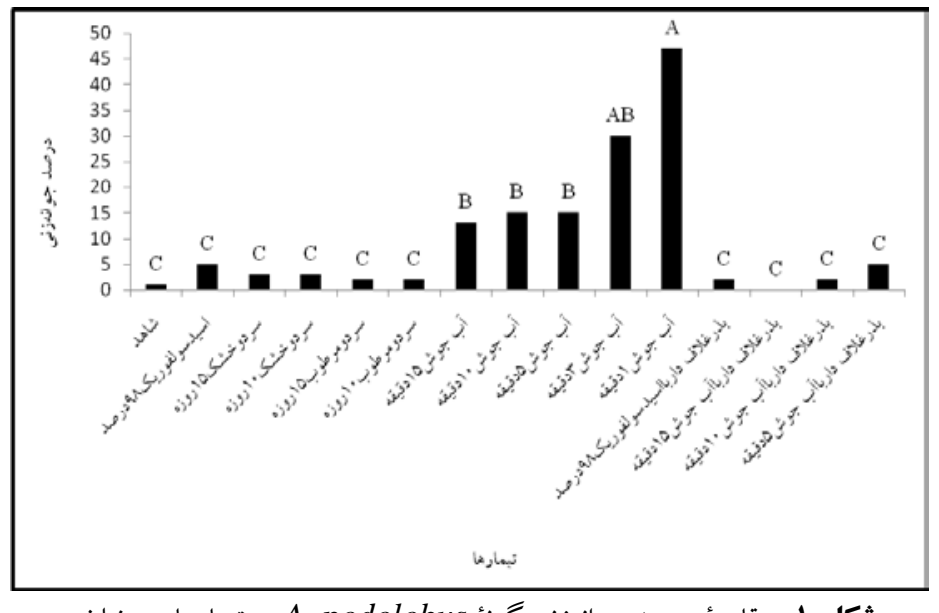

Fig. 1. Comparison of A. podolobus seed germination percentage in different treatments.

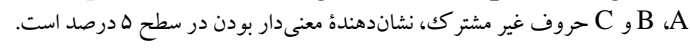

A, B and C letters subscribed, indicating a significant level of 5 percent.

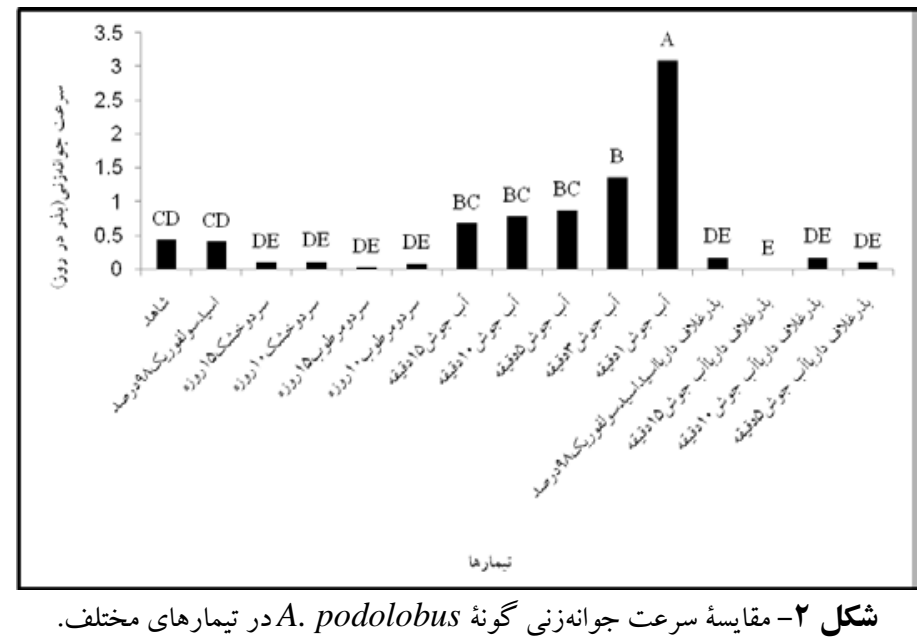

Fig. 2. Comparison of $A$. podolobus seed germination speed in different treatments.

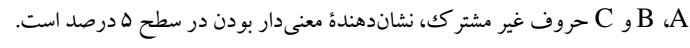

A, B and C letters subscribed, indicating a significant level of 5 percent.

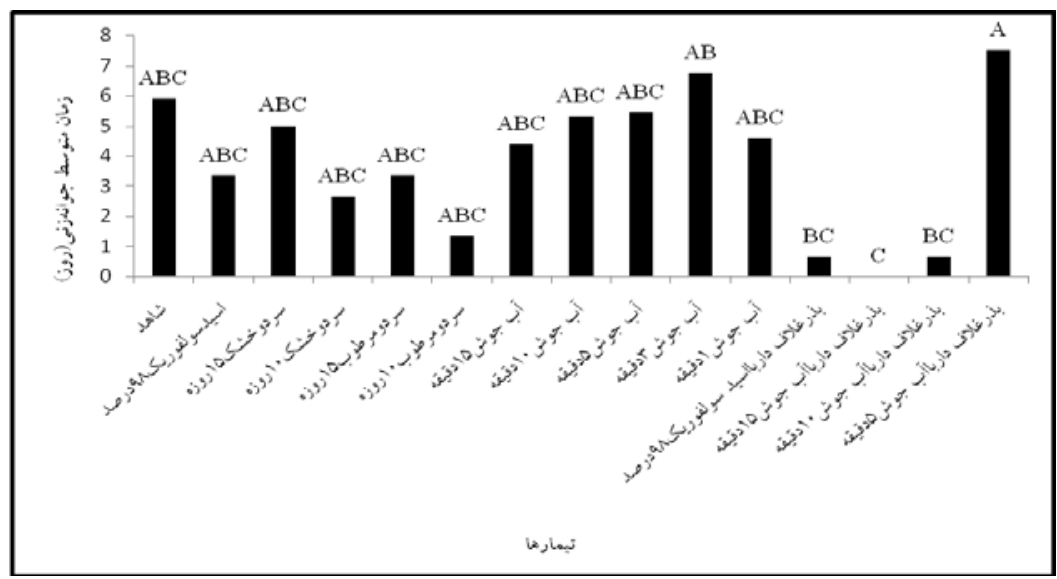

شكل r- مقايسٔ زمان متوسط جو انهزنى گونهُ A. podolobus در تيمارهاى مختلف.

Fig. 3. Comparison of A. podolobus seed germination mean time in different treatments.

$$
\text { حروف غير مشتر كث، نشاندهنده معنى دار بودن در سطح ه درصد است. C و B A }
$$

A, B and C letters subscribed, indicating a significant level of 5 percent. 


\section{REFERENCES}

Akramghaderi, F., Kamkar, B. and Soltani, A. 2008. Science and technology of seed. - Publication of Mashhad Jahad Daneshghahi. pp: 512.

Alebrahim, M.T., Rashedmohassel, M.H., Mighati, F. and Baghestani, M.A. 2010. Evaluation the methods of breaking seed dormancy and optimizing seed germination of Acroptilon repens. - J. Plant Prot. 4: 391-397.

Amouaghaie, R. 2007. Effect of lighting and age on seed germination of Ferula ovina. - Journal of Biological Sciences 18: 350-359.

Arbabian, S., Moghanlou, M. and Majd, A. 2009. Evaluation on different methods of seed treatment in Astragalus fridae. - Journal of Biological Sciences 7: 45-50.

Azarnivand, H. and Zare Chahouki, M.A. 2008. Rangeland Improvement. - University of Tehran Press. pp 240-242.

Esavand, H., Madaharefi, H. and Tavakolafshari, R. 2005. Investigation of dormancy and germination breaking of Astragalus siliquasus. - Iranian Journal of Rangelands and Forests Plant Breeding and Genetic Research 19: 6784.

Faizi, M.T. 2004. The final report autecology of Astragalus podolobus on Isfahan. - Institute of Forest and Rangelands. 91p.

Farhoudi, R., Makizadeh, M., Sharifzadeh, F. and Naghdibadi, H. 2006. Investigation of dormancy and germination braking of Rubia tinctourum. - Journal of Research and Construction 70: 2-7.

Fateh, A., Majnonhosseini, N., Madah, $\mathbf{H}$. and Sharifzadeh, F. 2005. Investigation of dormancy and germination braking of Astragalus tribuloides. - Iranian Journal of Rangelands and Forests Plant Breeding and Genetic Research 22: 345 - 360.

Hiss, A. 1990. A Study of the Germination Requirements of Astragalus agnicidus. Unpublished report presented to Andrea Pickart. Manager of Lanphere-Christenses Dunes Preserve.

Hosseini, S.A. 2012. The study on plant parameters and quality of some of Astragalus species in Golestan Natural Park. - Journal of Conservation and Utilization of Natural Resources 1: 45-56.

Karegar, M., Hosseini, M.V. and Rashedmorsal, M.H. 2013. Effect of different treatments on breaking dormancy and germination of seeds of Phalairs minor Retz. J. Plant Prot. 27: 128 -131.

Kazemi, S., Mardan, R., Lotfi Mavi, F. and Samadi Maman, S. 2008. Stimulation to germination and breaking Avena ludoviciana seeds dormancy by different treatments. - Iranian First National Seed Science and Technology Congress, Agriculture and Natural Resources, University of Gorgan.

Keshtkar, H.R., Azarnivand, H. and Shahriari, A. 2009. The effect of some treatments on seed dormancy and germination of Ferula assafoetida and Ferula gomosa. Journal of Rangeland Science 10: 281-290.

Khatirnameni, J. 2005. Evaluation the effect of Atriplex on soil of rangeland in Golestan province. - Iranian Journal of Range and Desert Research 12: 311-334.
آبجوش نشان مىدهد كه تنها بوستهُ سخت و نفوذ نايذير عامل خواب بذر نيست و وجود مواد بازدارندهُ شيميايى نيز تأثير زيادى بر ميزان جوانهزنى بذرهاى گياه A. podolobus دارند. درباب نتايج اين آزمايش مى توان به نتايج آزمايش Tavili و همكاران

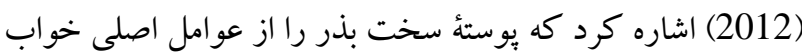
بذر در تيرهُ نيامداران مىدانند. Karegar و همكاران (2013) احتمال مىدهند كه افزايش ميزان جوانهزنى بذرها در اثر اعمال تيمارهاى آبداغ، بهدليل رهايى از محدوديت فيزيكى بوشش بذر

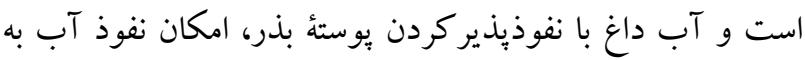
بذر را فراهم مى كند و با نرم كردن بيوسته، امكان متورم شدن بذر و رشد جنين را فر اهم مى كند. نتايج اين آزمايش نشان مىدهد بهترين تيمار براى شكستن A. خواب بذر و افزايش درصد و سرعت جوانهزنى در كونه (podolobus يافته هاى Karegar و همكاران (2013)، Farhodi و همكاران (2006)، kazemi و همكاران (2008)، Rehman و همكاران

$$
\text { (1999) و Tavili و همكاران (2012) مطابقت دارد. }
$$

\section{سياسگز ارى}

تحقيق حاضر بخشى از طرح ملى توسعه و ترويج گونه بومى Astragalus podolobus خاكك و ريز گردها در شمال شهرستان گنبد كاووس است كه جا دارد از معاونت علمى و فناورى رياست جمهورى و همجِنين ستاد توسعه فناورى آب، خشكسالى، فرسايش و محيط زيست تشكر كردد. 
Maassoumi, A. 2006. Astragalus of Iran. - Publication of Research Institute of Forest and Rang-elands. 786p.

Moghadam, M.R. 1998. Range and range management. Tehran University Publication. pp 470.

Moghimi, J. 2005. Introduce of some important range species suitable for pasture improvement and developpment of Iran. - Aroun Publication. pp 137-140.

Moshtaghyan, M.B., Keshtkar, H.R., Esmaeili Sharif, M. and Razavi S.M. 2009. Planting methods effect on Astragalus cyclophyllon establishment. - Journal of Range and Desert Research 16: 79-84.

Patanè, C. and Gresta, F. 2006. Germination of Astragalus hamosus and Medicago orbicularis as affected by seed coat dormancy breaking techniques. - J. Arid Environ. 67: 165-173.

Pouresmael, M. and Sharifi, M. 2003. Evaluation the effects of chilling and cytokines on seed treatment of Cumin. - Iranian Journal of Medical and Aromatic Plants 9: 183193.

Razavi, S.M. and Hajiboland, R. 2009. Dormancy breaking and germination of Prangos ferulacea seeds. - J Biosci. 3: 78-83.

Razmjoo, K., Razzazi, A., Khodaeian, N. and Askari, E. 2009. Breaking seed dormancy of Prangos uloptera DC. a medicinal plant of Iran. - Seed Sci. Technol. 37: 771775.

Rehman, S., Loescher, R.N. and Harris, P.J.C. 1999. Dormancy breaking and germination of (Acacia saliciina). - Seed Sci. Technol. 27: 553-557.

Safaian, R. and Azarnivand, H. 2010. The effect of some treatments on seed dormancy breaking and germination of Prangos ferulacea (L.) Lindl. - Journal of Range and Desert Research 17: 331-339.

Tajbakhsh, M. 1998. Seeds (study and control). - Ahoura Press, Ahvaz. pp 188.

Tavili, A., Abbassikhalaki, M. and Mameri, M. 2012. The effect of different seed treatment on germination and some characteristics of white Astragalus. - Seed Sci. Technol. 1: 64-72.

Tavili, A. 2014. Effect of some treatments on germination improvement of two Astragalus Species. - International Conference on Biological, Environment and Food Engineering (BEFE-2014) August 4-5, 2014 Bali (Indonesia), pp 29-30.

Tran, V. and Cavanagh, A.K. 1984. Structural aspects of seed dormancy and seed physiology; Vol 2. - D.R Murray. New York: Academic press.

Zarekia, S., Jafari, A.A., Zandiesfahan, E. and Fallahhosseini, L. 2013. Study on germination of some perennial herbaceous Astragalus. - Journal of Range and Desert Research 20: 88-100.

How to cite this article:

Agh, Kh., MohammadEsmaili, M., Hossinimoghaddam, H. and Mostafalo, H. 2017. The effect of different treatments on seed dormancy and germination of Astragalus podolobus. - Nova Biologica Rep. 4: 147-154.

$$
\text { برسى آث، محمداسماعيلى، م.، حسينىمقدم، ه. و مصطفىلو، ح. Astragalus podolobu }
$$

